\title{
Methods of Vector Control for Induction Motors
}

\author{
L. $\operatorname{Varga}^{1}$, M. Kuczmann ${ }^{2}$ \\ ${ }^{1}$ Audi Hungaria Zrt, Department of Petrol Engines \\ Audi Hungária út 1, 9027, Győr, Hungary \\ E-mail: mail@vargalaszlo.com \\ ${ }^{2}$ Széchenyi István University, Department of Automation \\ Egyetem tér 1, 9026, Gyốr, Hungary \\ E-mail: kuczmann@sze.hu
}

Abstract: This paper presents the electrical and mathematical models of the three phase asynchronous motors along with the introduction of the fieldoriented control model as well as the vector transformations needed for the introduction of the above mentioned terms. The objective of the present paper is to introduce the space vectors and how to build the field-oriented control for a given induction motor drive as well as the transformations and the modell of field oriented control.

Keywords: induction motor, vector control, Field Oriented Control

\section{Introduction}

The asynchronous motor drives are one of the most popular drive types of the industrial environment. Concerning its construction it is a simple drive without too many components, and it is also robust. Beside its positive electrical and mechanical parameters, it can also be operated easily and cost efficient way. The digital revolution in the last 30 years opened several new possibilities in the electronics such as the efficient speed control or the data collecting and analyzing systems. In the Fig. 1 the position of the asynchronous motors can be seen in the world of the electrical motors (the offset non related to the topic are not divided into further parts). 


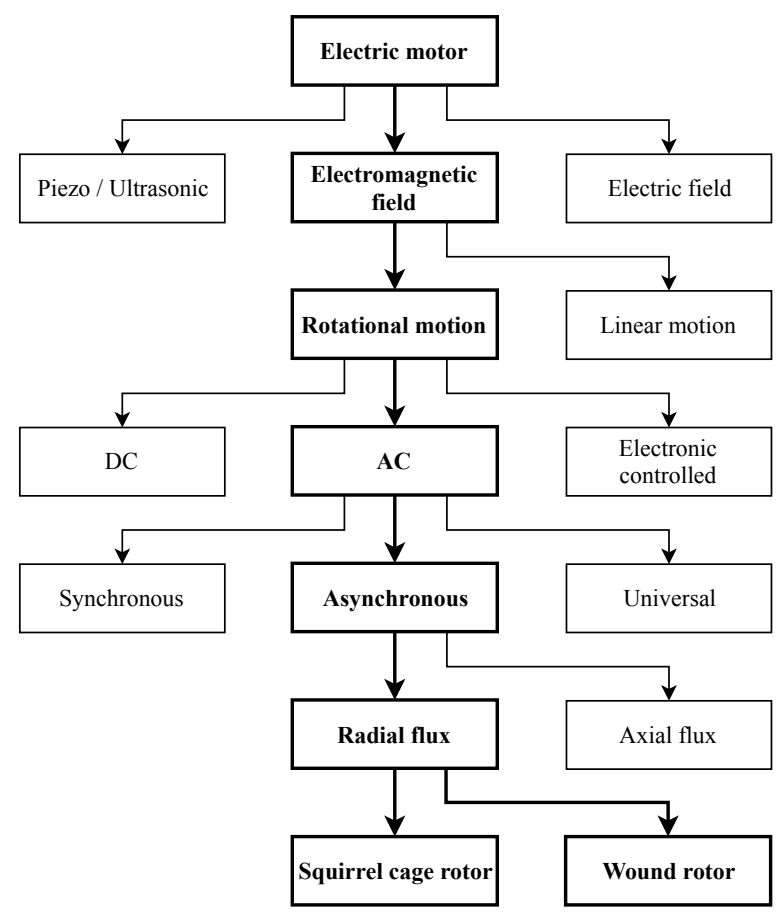

Figure 1. Type of the electrical motors.

Fig. 2 shows the lineage of the field-oriented model from the tree of the variable frequency drive [1].

\section{Model of the Asynchronous Motor}

In the following sections, one after the other, the models of the rotating asynchronous motors are presented. 


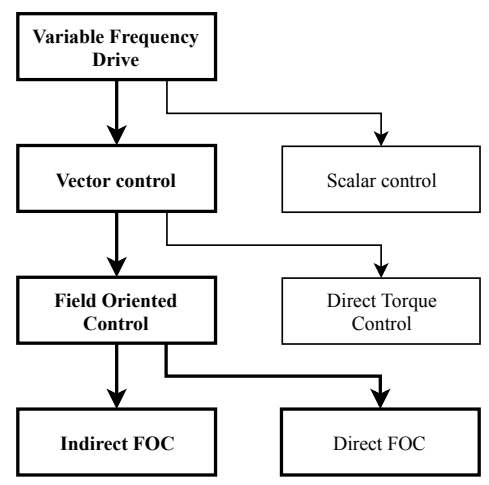

Figure 2. Tree of the Variable Frequency Drive.

\subsection{Ideal Transformer (ITF) voltage model}

The simplest way is when a large air gap transformer is considered - per phase - i.e. the asynchronous motors are ideal for a 1:1 reduced transfer. In this case during the reduction - in contrast with the normal transformer model - the so called efficient turn number of the transfer should be counted with (it is assumed in this case).

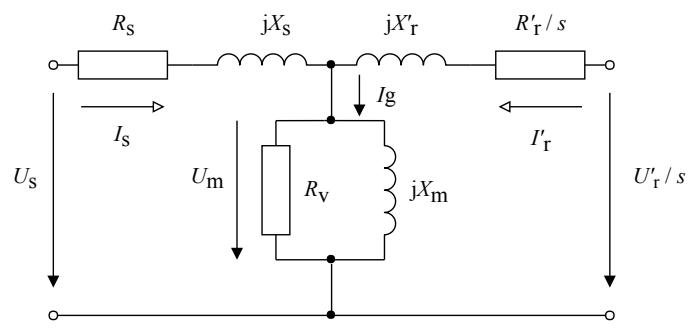

Figure 3. ITF model of asynchronous motor (one phase) [2]. 
The equations of the model are the following (the trivial correlations are concerned known) $[3,8]$ :

$$
\begin{gathered}
s=\frac{n_{1}-n}{n}, \\
U_{\mathrm{m}}=4.44 f_{\mathrm{r}} N_{\mathrm{r}} \varepsilon_{\mathrm{r}} \Phi, \\
U_{\mathrm{s}}=I_{\mathrm{s}} R_{\mathrm{s}}+I_{\mathrm{s}} \mathrm{j} X_{\mathrm{s}}+U_{\mathrm{m}}, \\
U_{\mathrm{mr}}=s U_{\mathrm{m}}=I_{\mathrm{r}}^{\prime} R_{\mathrm{r}}^{\prime}+I_{\mathrm{r}}^{\prime} \mathrm{j} s X_{\mathrm{r}}^{\prime}+U_{\mathrm{r}}^{\prime},
\end{gathered}
$$

then (4) can be divided by the slip (as it is an ideal transformer), and the result is the stator voltage equation coincides with the voltage equation from the rotating side with the slip so the two substituting sides can be joined together, i.e.

$$
U_{\mathrm{m}}=I_{\mathrm{r}}^{\prime} \frac{R_{\mathrm{r}}^{\prime}}{s}+I_{\mathrm{r}}^{\prime} \mathrm{j} X_{\mathrm{r}}^{\prime}+\frac{U_{\mathrm{r}}^{\prime}}{s} .
$$

Here $s$ is the slip, $n_{1}$ is the speed of the stator field, $n$ is the rotor speed of the rotating machine, $U_{\mathrm{s}}$ is the primer voltage, $U_{\mathrm{m}}$ is the inside voltage of the stator side, $f_{\mathrm{r}}$ is the frequency of the rotor field, $N_{\mathrm{r}}$ is the turn number of the rotor coil, $\varepsilon_{\mathrm{r}}$ is the efficiency factor of the rotor side, $\Phi$ is the flux, $L_{\mathrm{s}}$ is the leakage inductance of the stator, $L_{\mathrm{r}}$ is the inductance of the rotor (reduced), $R_{\mathrm{S}}$ is the coil resistance of the stator, $R_{\mathrm{r}}$ is the reduced coil resistance of the coil, $X_{\mathrm{s}}$ is the coil leakage reactance of the stator, $X_{\mathrm{r}}$ is the reduced coil target reactance of the rotor and the $U_{\mathrm{mr}}$ is the slip-fold inside voltage of the stator side, respectively. 


\subsection{Park-vector model}

The model represented in the prior section can give answer for only a few basic questions, so we need to generate the Park-vector form heading from the voltage equation. Look at first the voltage equations of the stator - they can be used for the rotor - with the condition that the coil resistance is concerned to be equal,

$$
\begin{gathered}
u_{\mathrm{sa}}=U_{\mathrm{sa}} \cos (\omega t), \\
u_{\mathrm{sb}}=U_{\mathrm{sb}} \cos \left(\omega t-120^{\circ}\right), \\
u_{\mathrm{sc}}=U_{\mathrm{sc}} \cos \left(\omega t-240^{\circ}\right) .
\end{gathered}
$$

Equations (6) - (8) are time functions and they do not describe the spatial arrangement but they describe the phase difference between the sine signals. Here $U_{\text {sa }}=$ $U_{\mathrm{sb}}=U_{\mathrm{sc}}$ are the amplitude of the time functions, $\omega=2 \pi f$ describe the angular frequency, and $t$ is the time. These time functions describe all phase voltages in stator winding and can be rewritten as the sum of the voltage drop in stator winding and the induced voltage of the flux change which are described by equations (9) - (14) (later the notation of the time $t$ is left, consequently).

To show this expressively Fig. 4 can be used, which shows conceptual circuit diagram of a squirrel cage induction motor. Of course, a similar schematic diagram can be drawn in case of a slip-ring induction motor, in which phase-circuits are equal on stator-side of the squirrel cage induction motor, but other equations would come about because of elements used for different phases of the rotor. 


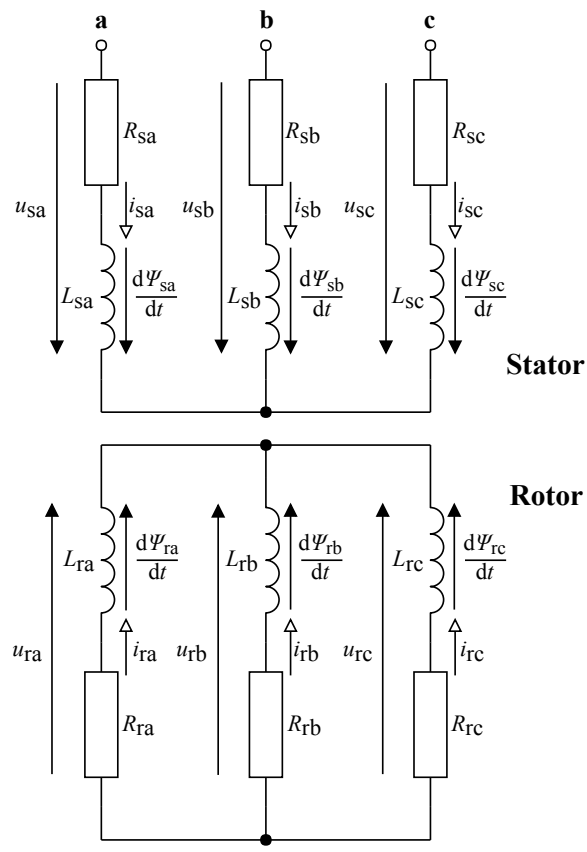

Figure 4. Simple scheme of the Squirrel Cage Induction Motor.

From the Fig. 4, it can be seen the how the stator voltage equations (9) - (11) along with the rotor voltage equations (12) - (14) are generated [3, 6, 9], i.e.

$$
\begin{aligned}
& u_{\mathrm{sa}}=i_{\mathrm{sa}} R_{\mathrm{s}}+\frac{\mathrm{d} \Psi_{\mathrm{sa}}}{\mathrm{d} t}, \\
& u_{\mathrm{sb}}=i_{\mathrm{sb}} R_{\mathrm{s}}+\frac{\mathrm{d} \Psi_{\mathrm{sb}}}{\mathrm{d} t},
\end{aligned}
$$




$$
\begin{aligned}
& u_{\mathrm{sc}}=i_{\mathrm{sc}} R_{\mathrm{s}}+\frac{\mathrm{d} \Psi_{\mathrm{sc}}}{\mathrm{d} t}, \\
& u_{\mathrm{ra}}=i_{\mathrm{ra}} R_{\mathrm{r}}+\frac{\mathrm{d} \Psi_{\mathrm{ra}}}{\mathrm{d} t}, \\
& u_{\mathrm{rb}}=i_{\mathrm{rb}} R_{\mathrm{r}}+\frac{\mathrm{d} \Psi_{\mathrm{rb}}}{\mathrm{d} t}, \\
& u_{\mathrm{rc}}=i_{\mathrm{rc}} R_{\mathrm{r}}+\frac{\mathrm{d} \Psi_{\mathrm{ca}}}{\mathrm{d} t},
\end{aligned}
$$

here $R_{\mathrm{s}}$ is the stator resistance of any phase coil $\left(R_{\mathrm{s}}=R_{\mathrm{sa}}=R_{\mathrm{sb}}=R_{\mathrm{sc}}\right), R_{\mathrm{r}}$ is the rotor resistance of any phase coil $\left(R_{\mathrm{r}}=R_{\mathrm{ra}}=R_{\mathrm{rb}}=R_{\mathrm{rc}}\right), i_{\mathrm{sa}}, i_{\mathrm{sb}}$ and $i_{\mathrm{sc}}$ are the currents of the stator coils, $i_{\mathrm{ra}}, i_{\mathrm{rb}}$ and $i_{\mathrm{rc}}$ are the currents of the rotor coils, $\Psi_{\mathrm{sa}}, \Psi_{\mathrm{sb}}$ and $\Psi_{\mathrm{sc}}$ are the flux of the stator phases and $\Psi_{\mathrm{ra}}, \Psi_{\mathrm{rb}}$ and $\Psi_{\mathrm{rc}}$ are the flux of the rotor phases.

Heading from the phase difference of the stator voltage equations (9) - (11) and introducing the following, complex unit vectors in the phase axis directions:

$$
\begin{gathered}
\overline{\boldsymbol{a}}^{0}=e^{\mathrm{j} 0^{\circ},} \\
\overline{\boldsymbol{a}}^{1}=e^{\mathrm{j} 120^{\circ},} \\
\overline{\boldsymbol{a}}^{2}=e^{\mathrm{j} 240^{\circ}},
\end{gathered}
$$

equations (9) - (11) can be brought to a mutual, the so called Park-vector form [9-11]:

$$
\overline{\boldsymbol{u}}_{\mathrm{s}}=\frac{2}{3}\left(\overline{\boldsymbol{a}}^{0} u_{\mathrm{sa}}+\overline{\boldsymbol{a}}^{1} u_{\mathrm{sb}}+\overline{\boldsymbol{a}}^{2} u_{\mathrm{sc}}\right) .
$$


As far as (9) - (11) are substituted into (18), the voltage equation (19) of the stator Park vector fixed to the coordinate system of the stator, can be written, i.e.

$$
\overline{\boldsymbol{u}}_{\mathrm{s}}=\overline{\boldsymbol{i}}_{\mathrm{s}} R_{\mathrm{s}}+\frac{\mathrm{d} \overline{\mathbf{\Psi}}_{\mathrm{s}}}{\mathrm{d} t}
$$

here $\overline{\boldsymbol{u}}_{\mathrm{s}}$ is the common voltage vector of stator, $\overline{\boldsymbol{i}}_{\mathrm{s}}$ is the common current vector of stator and $\bar{\Psi}_{\mathrm{s}}$ is the flux linkage of stator.

Using the analogy of (18) for the rotor, the Park vector form of the rotor fixed to the coordinate system of the rotating part can be obtained as

$$
\overline{\boldsymbol{u}}_{\mathbf{r}}=\overline{\boldsymbol{i}}_{\mathbf{r}} R_{\mathrm{r}}+\frac{\mathrm{d} \overline{\mathbf{\Psi}}_{\mathbf{r}}}{\mathrm{d} t}
$$

here $\overline{\boldsymbol{u}}_{\mathrm{r}}$ is the common voltage vector of rotor, $\overline{\boldsymbol{i}}_{\mathrm{r}}$ is the common current vector of rotor and $\overline{\mathbf{\Psi}}_{\mathrm{s}}$ is the flux linkage of rotor.

For the graphic representation of the Park vector can be applied the analogy of equations (19) and (20) and generate a common formula [11]. This equation (21) can be used for the stator and for the rotor too [11].

$$
\overline{\boldsymbol{u}}=\overline{\boldsymbol{i}} R_{\mathrm{r}}+\frac{\mathrm{d} \overline{\mathbf{\Psi}}}{\mathrm{d} t}
$$

The interpretation of the equation (21) is represented by the Fig. 5. In this interpretation the $\overline{\boldsymbol{i}}$ current vector can be used better instead of $\overline{\boldsymbol{u}}$ voltage vector because further calculations are simpler.

As an example in Fig. 5, three phase $(a, b, c)$ with identical frequency and amplitude are used, where the sine signals are shifted by $120^{\circ}$ and at $\omega t=110^{\circ}$, 


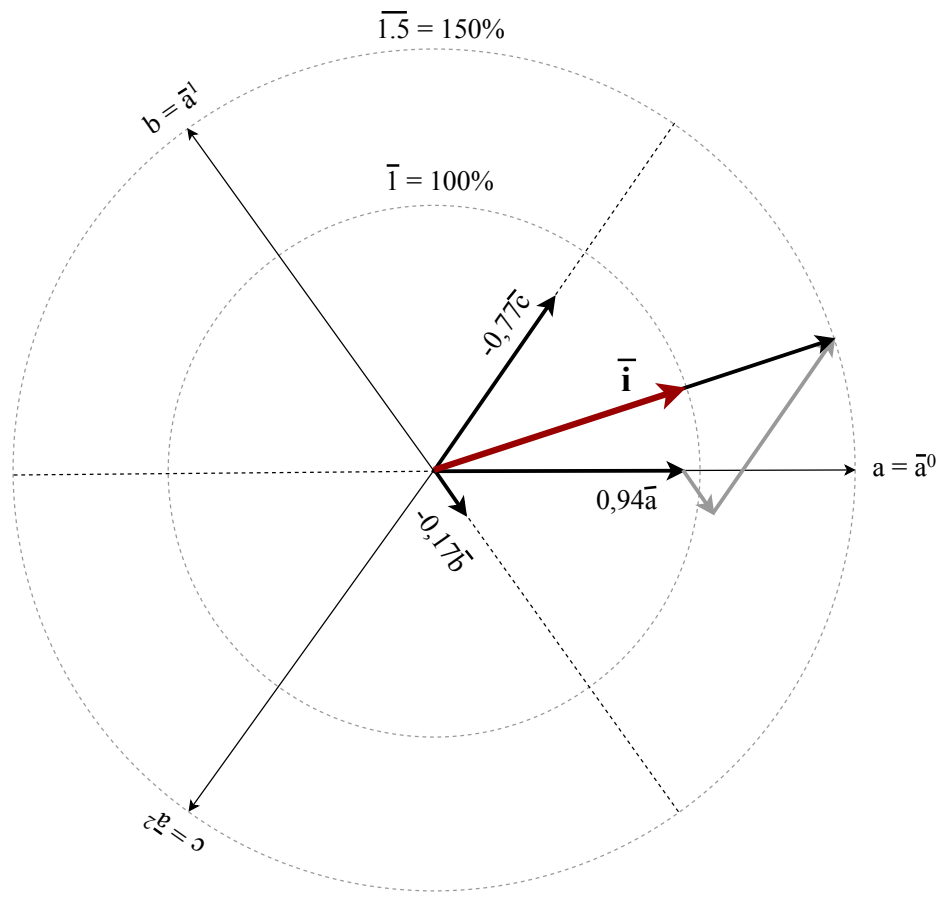

Figure 5. Park-vector scheme.

$i_{a}=0.94, i_{b}=-0.17$ and $i_{c}=-0.77$ can be interpreted as the momentary result of the adequated phase power (compared to 1 , the whole, $i_{a}+i_{b}+i_{c}=0$ ) as well as the $\bar{i}$ which is the resultive Park-vector current.

The voltage equation (21) is valid for the stator as well as for the rotor, but in both cases, it stands for a coordinate system which is fixed to itself. For the general examination the so called mutual coordinate system is needed. By its help, the voltage and flux equations of the asynchronous machine can be used for the rotor and also for the stator, separately. 


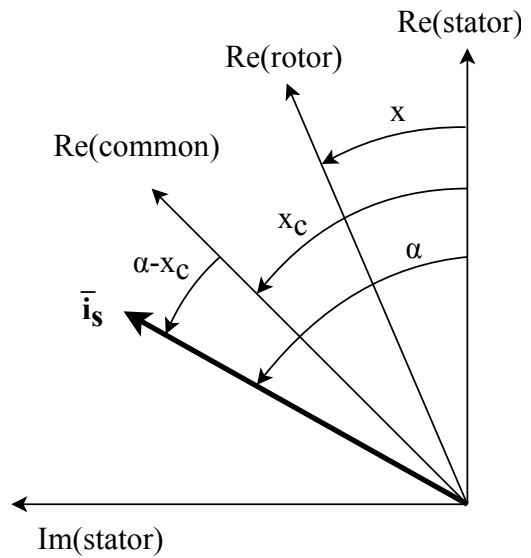

Figure 6. Common coordinates system of the stator.

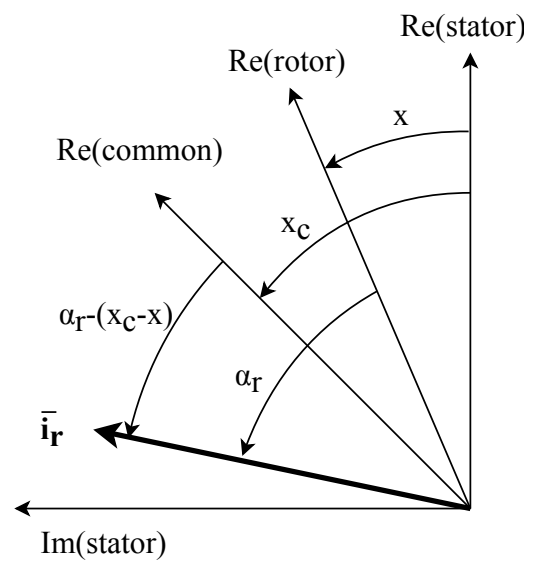

Figure 7. Common coordinates system of the rotor. 
According to Fig. 6 [11] the current vector of the stator in the mutual coordinate system is

$$
\overline{\boldsymbol{i}}_{\mathrm{s}}^{*}=\overline{\boldsymbol{i}}_{\mathrm{s}} e^{-\mathrm{j} x_{\mathrm{c}}}
$$

which is transformed by the additional substitution

$$
\bar{i}_{\mathrm{s}}=\bar{i}_{\mathrm{s}}^{*} e^{\mathrm{j} x_{\mathrm{c}}}
$$

where $*$ is the sign of the transformation to the common coordinate system.

With this analogy, according to Fig. 7 [11] the current vectors in the mutual coordinate system of the rotor are the following:

$$
\begin{gathered}
\overline{\boldsymbol{i}}_{\mathbf{r}}^{*}=\overline{\boldsymbol{i}}_{\mathrm{r}} e^{-\mathrm{j}\left(x_{\mathrm{c}}-x\right)}, \\
\overline{\boldsymbol{i}}_{\mathbf{r}}=\overline{\boldsymbol{i}}_{\mathbf{r}}^{*} e^{\mathrm{j}\left(x_{\mathrm{c}}-x\right)} .
\end{gathered}
$$

Being back replaced into the equation of (21), and after some mathematical conversions, the asynchronous machine's basic equations with Park-vector can be brought to the following form in the mutual coordinate system (without an asterisk):

$$
\begin{gathered}
\overline{\boldsymbol{u}}_{\mathrm{s}}=\overline{\boldsymbol{i}}_{\mathrm{s}} R_{\mathrm{s}}+\frac{\mathrm{d} \overline{\boldsymbol{\Psi}}_{\mathrm{s}}}{\mathrm{d} t}+\mathrm{j} \omega_{\mathrm{c}} \overline{\boldsymbol{\Psi}}_{\mathrm{s}}, \\
\overline{\boldsymbol{u}}_{\mathbf{r}}=\overline{\boldsymbol{i}}_{\mathrm{r}} R_{\mathrm{r}}+\frac{\mathrm{d} \overline{\boldsymbol{\Psi}}_{\mathbf{r}}}{\mathrm{d} t}+\mathrm{j}\left(\omega_{\mathrm{c}}-\omega\right) \overline{\boldsymbol{\Psi}}_{\mathrm{r}},
\end{gathered}
$$

where $\omega$ is the electric angular velocity of the rotor and $\omega_{c}$ is the electrical angular velocity of the mutual coordinate-system. 


\subsection{Flux equivalent circuit}

The next step of the system analysis is - looking ahead the future phases of the research - the exploration of the flux relationships in the machine model. The transformed power vectors into the mutual coordinate system, also foreshowed in section 2.2. are being used in the flux equations which have their explanation in Fig. 8.

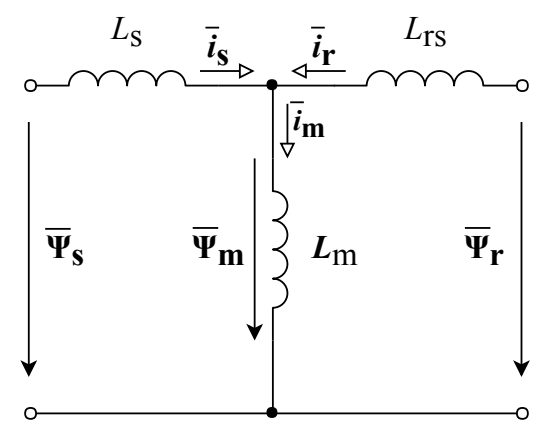

Figure 8. The flux equivalent circuit.

Here $\bar{\Psi}_{\mathbf{s}}, \overline{\mathbf{\Psi}}_{\mathbf{m}}, \overline{\mathbf{\Psi}}_{\mathbf{r}}$ are the flux vectors, and $\overline{\boldsymbol{i}}_{\mathbf{s}}, \overline{\boldsymbol{i}}_{\mathbf{m}}, \overline{\boldsymbol{i}}_{\mathbf{r}}$ are the current vectors. All of them are transformed vectors to the mutual coordinate system of the stator, rotor and the mutual magnetization flux and the current (without $*$ ).

By the help of Fig. 8 [3], it can be seen that the total (F index: "full") inductivity of the stator is

$$
L_{\mathrm{sF}}=L_{\mathrm{s}}+L_{\mathrm{m}},
$$

and the total inductivity of the rotor is

$$
L_{\mathrm{rF}}=L_{\mathrm{rs}}+L_{\mathrm{m}},
$$


where $L_{\mathrm{rs}}$ is the leakage inductivity of the rotor, $L_{\mathrm{m}}$ is the inductivity of the mutual magnetization, $L_{\mathrm{s}}$ is the leakage inductivity of the stator.

Using the equations (23), (25) and (28), (29), see in [3], the flux equations belonging to the mutual coordinate system can be generated, which are needed for the extension of the Park-vector model:

$$
\begin{aligned}
& \overline{\mathbf{\Psi}}_{\mathbf{s}}=L_{\mathrm{sF}} \overline{\boldsymbol{i}}_{\mathbf{s}}+L_{\mathrm{m}} \overline{\boldsymbol{i}}_{\mathbf{r}} \\
& \overline{\boldsymbol{\Psi}}_{\mathbf{r}}=L_{\mathrm{m}} \overline{\boldsymbol{i}}_{\mathbf{s}}+L_{\mathrm{rF}} \overline{\boldsymbol{i}}_{\mathbf{r}}
\end{aligned}
$$

The electrical and mathematical models - described until this section - can be used after some condition for the rotating part of the squirrel cage motor. By its help and using the mechanical models of the asynchronous machine - the detailed explanation is not part of this paper, see in [6] - as well as the help of some further transformations, modern and vector field-oriented regulations can be generated.

\section{Vector control for Induction Motor}

The basic idea of the vector control, or its other name, field-oriented control (FOC) is that it the stator's three-phase input is splitted up into 2 orthogonal components that 2 components can appoint one vector. These 2 vectors are the torque and the magnetic flux.

This basic idea goes back to the conception of the former DC motors where the machine's construction lets control the torque (and/or the speed control) as well as the magnetic field independently from each other. This induces the wide dynamic range of the DC machine and also its stability.

On the other hand, the AC machine is non-linear and multi variable system in which the variable parts depend strongly on the outer parameters and on each other parameters as well (such as temperature, magnetic hysteresis, current frequency etc.). Its mathematical model is complicated by retroaction and by cross-effects. It follows 
from these that the power components which generate the torques cannot be separated with trivial methods.

The regulation of the induction machine with 2 independent components can be attached into a simple loop circle, which can be seen in Fig. 9. From the connections in Fig. 9 and the section 2 the basic scheme of the field-oriented regulations can be composed.

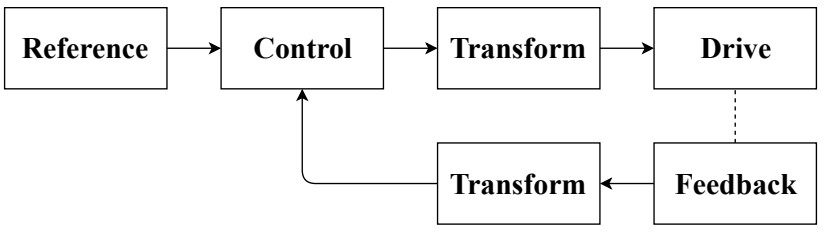

Figure 9. Diagram of the Induction Motor control.

\subsection{Transformation}

The purpose is the application of such a transformation model which makes possible the regulation of time variant parameters as time invariant variables which modifies the Fig. 9 as follows $[1,7]$.

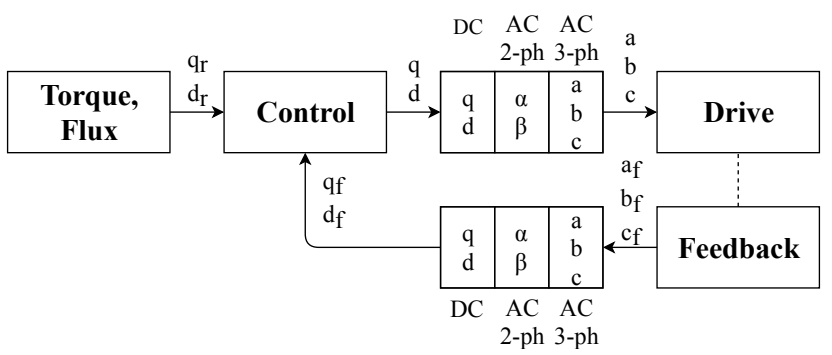

Figure 10. Transformations in the FOC model. 
The reference parameters on Fig. 10 are the input Torque $\left(q_{r}\right)$ and Flux $\left(d_{r}\right)$ through a control function the Torque $\left(q_{f}\right)$ and Flux $\left(d_{f}\right)$ which are coming back from the feedback line, from these are the input parameters of the transformation model $[4,6,9]$. It can be seen from mathematical and electric point of view that the well-manageable and in time non-changing values are the regulatory parameters in the regulation move.

\subsubsection{Clarke and inverse Clarke transformation}

As it is experienced in the section 2 the sine signals can get onto the three phase asynchronous motor coils. These sine signals are in frequency and amplitude consistent but they are shifted in phase to each other with $120^{\circ}$.

With the Clarke transformation it is possible to transform vectors $\overline{\boldsymbol{a}}, \overline{\boldsymbol{b}}, \overline{\boldsymbol{c}}$ (three-phase) vectors to orthogonal $\bar{\alpha}$ and $\bar{\beta}$ (two-phase) vectors. These vectors appoint an $\overline{\boldsymbol{i}}$ vector in the two dimensional space - this is the Park-vector, itself.

The transformation can be conducted with the following steps in form of a vector from the Fig. 5 (furthermore the Park-vector) :

- the axis of phase $\alpha$ of Park-vector is being turned with the vectors $\overline{\boldsymbol{a}}$ and $\overline{\boldsymbol{i}}$ into a $x$ axis of an orthogonal 2 dimensional coordinate system;

- the transformation vector $\overline{\boldsymbol{a}}$ is itself the vector $\overline{\boldsymbol{a}}$ of the turned phase axis $\alpha$;

- the transformation vector $\bar{\beta}$ is cut by the vectors $\overline{\boldsymbol{a}}$ and $\overline{\boldsymbol{i}}$ from the $y$ axis of the coordinate system.

In practice the vector $\overline{\boldsymbol{\alpha}}$ and the Park vector $\overline{\boldsymbol{i}}$ appoint the Clarke-transform $\bar{\beta}$ vector, which is presented in the Fig. 11.

The transformation in matrix form is as follow $[5,12]$ :

$$
\left[\begin{array}{l}
\boldsymbol{i}_{\boldsymbol{\alpha}} \\
\overline{\boldsymbol{i}}_{\boldsymbol{\beta}}
\end{array}\right]=\frac{2}{3}\left[\begin{array}{ccc}
1 & -\frac{1}{2} & -\frac{1}{2} \\
0 & \frac{\sqrt{3}}{2} & -\frac{\sqrt{3}}{2}
\end{array}\right]\left[\begin{array}{l}
\overline{\boldsymbol{i}}_{\mathbf{a}} \\
\overline{\boldsymbol{i}}_{\mathbf{b}} \\
\overline{\boldsymbol{i}}_{\mathbf{c}}
\end{array}\right],
$$




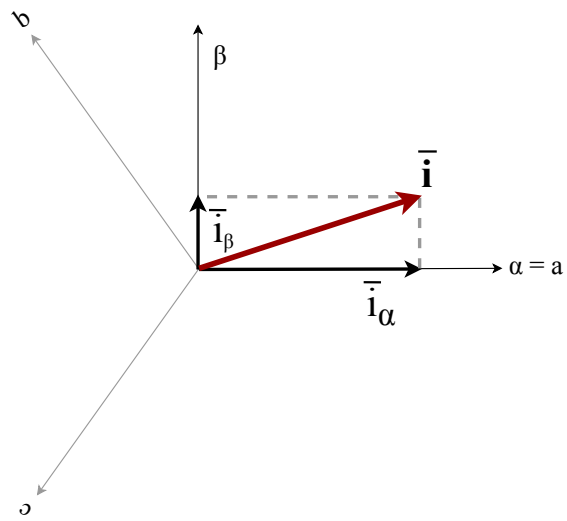

Figure 11. The Clarke transformation.

which is in the feedback line of the Fig. 10 [12], so an inverse transformation is needed in the control line that is the inverse Clarke transformation.

In case of a two phases system conversion to a three phase system, the following matrix is needed $[11,12]$ :

$$
\left[\begin{array}{c}
\overline{\boldsymbol{i}}_{\mathbf{a}} \\
\overline{\boldsymbol{i}}_{\mathbf{b}} \\
\overline{\boldsymbol{i}}_{\mathbf{c}}
\end{array}\right]=\left[\begin{array}{cc}
1 & 0 \\
-\frac{1}{2} & \frac{\sqrt{3}}{2} \\
-\frac{1}{2} & -\frac{\sqrt{3}}{2}
\end{array}\right]\left[\begin{array}{c}
\overline{\boldsymbol{i}}_{\boldsymbol{\alpha}} \\
\overline{\boldsymbol{i}}_{\beta}
\end{array}\right] .
$$

\subsubsection{Park and Park ${ }^{-1}$ transformation}

After the Clarke transformation the two phase component can be still hardly regulated and it is still alternating. Due to this, after the phase transformation the coordinatesystem's transformation should also be performed which will rotate synchronous with the stator's three-phase rotating field. From these we can receive the needed $q$ 
Torque and the $d$ Flux in time variant components. These can be easily managed from electrical point of view.

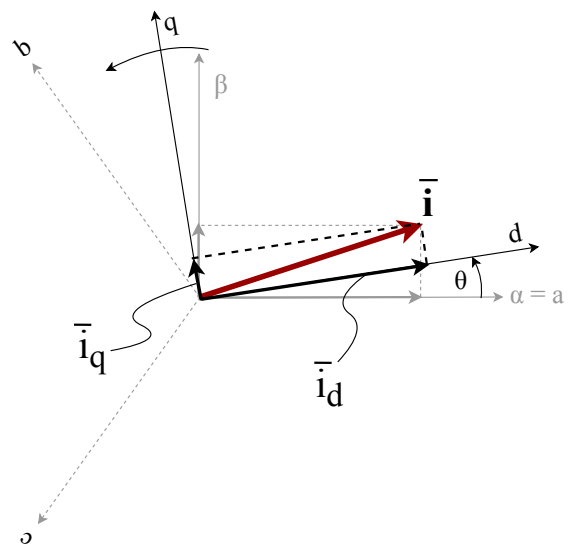

Figure 12. Park transformation [12].

After the presented Park transformation, a synchronous rotating coordinate system will be generated where $\theta$ is the electrical angle [12]:

$$
\left[\begin{array}{l}
\overline{\boldsymbol{i}}_{\mathbf{d}} \\
\overline{\boldsymbol{i}}_{\mathbf{q}}
\end{array}\right]=\frac{2}{3}\left[\begin{array}{cc}
\cos (\theta) & \sin (\theta) \\
-\sin (\theta) & \cos (\theta)
\end{array}\right]\left[\begin{array}{l}
\overline{\boldsymbol{i}}_{\boldsymbol{\alpha}} \\
\overline{\boldsymbol{i}}_{\boldsymbol{\beta}}
\end{array}\right] .
$$

In the inverse form of the transformation to the stator coordinate system is returned where again the two phase components appear that are time variant [12]:

$$
\left[\begin{array}{l}
\overline{\boldsymbol{i}}_{\boldsymbol{\alpha}} \\
\overline{\boldsymbol{i}}_{\boldsymbol{\beta}}
\end{array}\right]=\frac{2}{3}\left[\begin{array}{cc}
\cos (\theta) & -\sin (\theta) \\
-\sin (\theta) & \cos (\theta)
\end{array}\right]\left[\begin{array}{l}
\overline{\boldsymbol{i}}_{\mathbf{d}} \\
\overline{\boldsymbol{i}}_{\mathbf{q}}
\end{array}\right] .
$$




\subsection{Field-Oriented Control}

In Fig. 10 the basic model is presented. It can be brought to the following form by the help of the Clarke and the Park transformations:

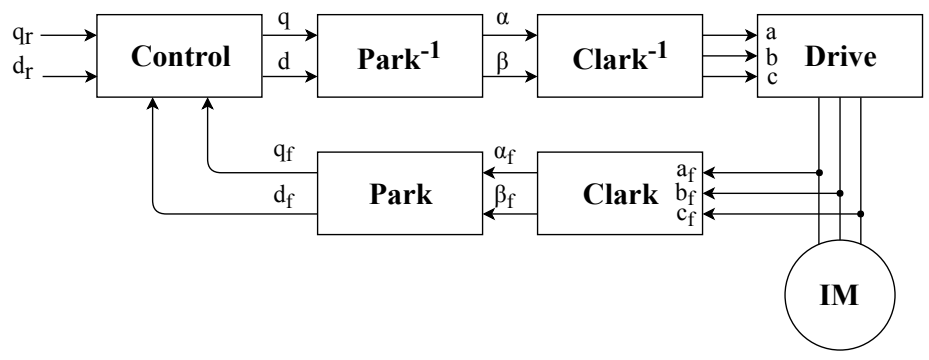

Figure 13. Simple FOC model [3, 5, 9-12].

Fig. 13 represents a simple field-oriented regulation model where the transformations are being built according to the section 3.1., and they can be brought to a mutual matrix shape according to the equation (36) [12]

$$
\left[\begin{array}{c}
\overline{\boldsymbol{i}}_{\mathbf{d}} \\
\overline{\boldsymbol{i}}_{\mathbf{q}}
\end{array}\right]=\frac{2}{3}\left[\begin{array}{ccc}
\cos (\theta) & \cos (\theta-\lambda) & \cos (\theta+\lambda) \\
-\sin (\theta) & -\sin (\theta-\lambda) & -\sin (\theta+\lambda)
\end{array}\right]\left[\begin{array}{c}
\overline{\boldsymbol{i}}_{\mathbf{a}} \\
\overline{\boldsymbol{i}}_{\mathbf{b}} \\
\overline{\boldsymbol{i}}_{\mathbf{c}}
\end{array}\right]
$$

as well as the matrix shape of the inverse transformation is seen as [12]

$$
\left[\begin{array}{c}
\overline{\boldsymbol{i}}_{\mathbf{a}} \\
\overline{\boldsymbol{i}}_{\mathbf{b}} \\
\overline{\boldsymbol{i}}_{\mathbf{c}}
\end{array}\right]=\frac{2}{3}\left[\begin{array}{cc}
\cos (\theta) & -\sin (\theta) \\
\cos (\theta-\lambda) & -\sin (\theta-\lambda) \\
\cos (\theta+\lambda) & -\sin (\theta+\lambda)
\end{array}\right]\left[\begin{array}{l}
\boldsymbol{i}_{\mathbf{d}} \\
\dot{\boldsymbol{i}}_{\mathbf{q}}
\end{array}\right]
$$

in which $\lambda=\frac{2 \pi}{3}$. 
The presented basic model has several enlargement possibilities for the regulation and also for the feedback line, but these refer to specific models.

\section{Conclusion}

The paper concludes that the vector control for induction motor can be introduced using the scheme of the induction motor and can be prepared transformation matrices for quick calculations of the current vectors. The modells and the calculations will be explained and simulated in the following papers.

\section{References}

[1] B. Srinu Naik, Comparison of Direct and Indirect Vector Control of Induction Motor, International Journal of New Technologies in Science and Engineering, 2 (1) (2014) pp. 110-131.

[2] Y. S. Chistyakov, E. V. Kholodova, A. S. Minin, H.-G. Zimmermann, Alois Knoll: Modeling of Electric Power Transformer Using Complex - Valued Neural Networks, Energy Procedia, 12 (2011) pp. 638 - 647. doi:10.1016/j.egypro.2011.10.087

[3] R. Krishnan, Electric Motor Drives, Modeling, Analysis, and Control, First Indian Reprint, Pearson Education, 2003.

[4] A. Chikhi, M. Djarallah, K. Chikhi, A Comparative Study of Field-Oriented Control and Direct-Torque Control of Induction Motors Using An Adaptive Flux Observer, Serbian Journal of Electrical Engineering, 7 (1) (2010) pp. 41-55. doi: 10.2298/SJEE1001041C

[5] Venu Gopal B T, Comparison Between Direct and Indirect Field Oriented Control of Induction Motor, International Journal of Engineering Trends and Technology (IJETT), 43 (6) (2017) pp. 364-369. doi:10.14445/22315381/IJETT-V43P260

[6] I. Boldea, S. A. Nasar: Electric Drives, 3rd Edition, CRC Press, New York, 2016. 
[7] Kang-Zhi Lui, Masashi Yokoo, Keiichiro Kondo, Tadanao Zamma: New Adaptive Vector Control Methods for Induction Motors with Simpler Structure and Better Performance, Control Theory Tech, Chiba (Japan), 13 (2) (2015) pp. 173-183. doi: $10.1007 / \mathrm{s} 11768-015-4153-\mathrm{z}$

[8] K. P. Kovács, Transient Processes of Electrical Machines, Technical Press, Budapest, 1970. (in Hungarian)

[9] J. Pyrhonen, V. Hrabovcova, R. S. Semken: Electrical Machine Drives Control: An Introduction, 1st Edition, John Wiley \& Sons Ltd., Noida, India, 2016.

[10] B. Akin, Simple Derivative-Free Nonlinear State Observer for Sensorless AC Drives, IEEE/ASME Transactions on Mechatronics, 11 (5) (2006) pp. 634-643. doi: 10.1109/TMECH.2006.882996

[11] R. De Doncker, D.W.J. Pulle, A. Veltman: Advanced Electrical Drives (Analysis, Modeling, Control), Springer, Germany-Australia-Netherlands, 2011.

[12] P. Vas: Sensorless Vector and Direct Torque Control, Oxford University Press, New York - Tokyo, 1998. 